\title{
Minotaur is critical for primary piRNA biogenesis
}

\author{
VASILY V. VAGIN, ${ }^{1,4}$ YANG YU, ${ }^{1,4}$ ANNA JANKOWSKA, ${ }^{1,4}$ YICHENG LUO, ${ }^{1,2}$ KAJA A. WASIK, ${ }^{1}$ \\ COLIN D. MALONE, ${ }^{1}$ EMILY HARRISON, ${ }^{1}$ ADAM ROSEBROCK, ${ }^{1}$ BARBARA T. WAKIMOTO, ${ }^{3}$ \\ DELPHINE FAGEGALTIER, ${ }^{1}$ FELIX MUERDTER, ${ }^{1}$ and GREGORY J. HANNON ${ }^{1,5}$ \\ ${ }^{1}$ Watson School of Biological Sciences, Howard Hughes Medical Institute, Cold Spring Harbor Laboratory, Cold Spring Harbor, New York 11724 , USA \\ ${ }^{2}$ College of Pharmaceutical Science, Jilin University, Changchun, Jilin 130021, China P.R. \\ ${ }^{3}$ Department of Biology and Center for Developmental Biology, University of Washington, Seattle, Washington 98195, USA
}

\begin{abstract}
Piwi proteins and their associated small RNAs are essential for fertility in animals. In part, this is due to their roles in guarding germ cell genomes against the activity of mobile genetic elements. piRNA populations direct Piwi proteins to silence transposon targets and, as such, form a molecular code that discriminates transposons from endogenous genes. Information ultimately carried by piRNAs is encoded within genomic loci, termed piRNA clusters. These give rise to long, single-stranded, primary transcripts that are processed into piRNAs. Despite the biological importance of this pathway, neither the characteristics that define a locus as a source of piRNAs nor the mechanisms that catalyze primary piRNA biogenesis are well understood. We searched an EMS-mutant collection annotated for fertility phenotypes for genes involved in the piRNA pathway. Twenty-seven homozygous sterile strains showed transposon-silencing defects. One of these, which strongly impacted primary piRNA biogenesis, harbored a causal mutation in CG5508, a member of the Drosophila glycerol-3-phosphate O-acetyltransferase (GPAT) family. These enzymes catalyze the first acylation step on the path to the production of phosphatidic acid (PA). Though this pointed strongly to a function for phospholipid signaling in the piRNA pathway, a mutant form of CG5508, which lacks the GPAT active site, still functions in piRNA biogenesis. We have named this new biogenesis factor Minotaur.
\end{abstract}

Keywords: Drosophila; GPAT; piRNA; transposon

\section{INTRODUCTION}

Most animal genomes are heavily populated by transposable elements whose unfettered activity has the potential to negatively impact genome integrity. Particularly in germ cells, the activity of transposons must be tightly constrained not only to prevent the accumulation of deleterious mutations over evolutionary time spans, but also because a defect in transposon control is often associated with catastrophic germ cell loss (Khurana and Theurkauf 2008).

In animals, a small RNA-based innate immune system plays an important role in protecting germ cell genomes against unwanted transposon activity (Aravin et al. 2007; Ghildiyal and Zamore 2009; Siomi et al. 2011). This RNAi-related response depends upon the PIWI clade of Argonaute proteins and their associated small RNAs, the piRNAs (PIWI-interacting RNAs). piRNAs can be divided into two classes, primary and secondary (Brennecke et al. 2007; Malone et al. 2009). Primary piRNAs are derived from discrete genomic loci, termed piRNA clusters (Aravin et al. 2003; Brennecke et al.

\footnotetext{
${ }^{4}$ These authors contributed equally to this work.

${ }^{5}$ Corresponding author

E-mail hannon@cshl.edu

Article published online ahead of print. Article and publication date are at http://www.rnajournal.org/cgi/doi/10.1261/rna.039669.113.
}

2007). The sequence content of these loci specifies the silencing targets of the piRNA pathway, essentially serving as a genetic definition that discriminates transposons from genes. piRNA clusters apparently generate long, single-stranded precursors, which are parsed into mature piRNA species through multiple nucleolytic cleavages (Brennecke et al. 2007; Siomi et al. 2011). piRNAs are loaded into Piwi proteins and direct them to silence complementary targets, at least in part, via a cleavage reaction that is analogous to canonical RNAi. One variation specific to the piRNA pathway is that, at least in some cases, target recognition leads to the production of a new piRNA derived from the substrate RNA, with its $5^{\prime}$ end formed by PIWI-catalyzed cleavage (Brennecke et al. 2007; Gunawardane et al. 2007). piRNAs formed in this manner are termed "secondary" piRNAs and are components of an adaptive loop called the "ping-pong cycle," which shapes the content of piRNA populations depending upon the abundance of individual transposon mRNAs (Brennecke et al. 2008).

The mechanism by which piRNA cluster transcripts are defined and processed into primary piRNAs is still largely mysterious. It has been proposed that at least two nucleolytic reactions are required to form primary piRNAs (Brennecke et al. 2007). An initial endonucleolytic cleavage is thought to generate piRNA $5^{\prime}$ ends, while biochemical evidence suggests 
that mature $3^{\prime}$ ends are formed by exonucleolytic trimming once longer precursors have been loaded into PIWI proteins (Kawaoka et al. 2011).

Though their precise biochemical functions remain unclear, a number of factors have been implicated in primary piRNA biogenesis, mainly through studies in Drosophila. These include a phosphodiesterase (Zucchini), a putative RNA helicase (Armitage), a number of proteins containing Tudor motifs (Vreteno and Yb-family members), and the FKPB-family member Shutdown (Haase et al. 2010; Olivieri et al. 2010, 2012; Handler et al. 2011; Saito et al. 2011; Zamparini et al. 2011; Preall et al. 2012). At least in Drosophila follicle cells, $\mathrm{Yb}$ defines a specific cytoplasmic structure, termed the $\mathrm{Yb}$ body, which has been implicated as a potential site of piRNA biogenesis (Saito et al. 2011). The $\mathrm{Yb}$ body also contains Armitage and Vreteno, and there is a correlation between disruption of this structure and a defect in primary piRNA formation or stability (Handler et al. 2011). In Drosophila germ cells, $\mathrm{Yb}$ family proteins reside in nuage, which contain a number of proteins essential to the piRNA pathway (Handler et al. 2011). As with $\mathrm{Yb}$ bodies, the localization of piRNA pathway components to nuage is strongly correlated with the effective operation of the pathway (Lim and Kai 2007).

PIWI proteins contain sites of arginine methylation near their amino termini, and these modifications drive binding to proteins containing Tudor domains (Chen et al. 2011). It is currently thought that such interactions aid in the concentration of piRNA pathway factors in RNP domains, such as chromatoid bodies, $\mathrm{Yb}$ bodies, and nuage (Pek et al. 2012; Pillai and Chuma 2012). As examples, the Tudor-containing proteins, Krimper, Spindle-E, and Qin/Kumo, are all essential and nonredundant components of the ping-pong cycle that are essential for maintaining the nuage localization of Aubergine and Ago3 in Drosophila germ cells (Malone et al. 2009; Anand and Kai 2011; Zhang et al. 2011).

Zucchini is important for primary piRNA biogenesis in both Drosophila germ cells and in somatic follicle cells (Malone et al. 2009). In the absence of Zuc, primary piRNA populations plummet with a corresponding increase in the presence of longer RNAs corresponding to piRNA clusters (Haase et al. 2010). Unlike other proteins implicated in primary piRNA biogenesis, Zucchini does not localize to $\mathrm{Yb}$ bodies or nuage. Instead, it is found on the mitochondrial outer membrane with its phoshodiesterase domain projecting toward the cytoplasm (Saito et al. 2009). A key role for Zucchini catalytic activity in piRNA biogenesis was first indicated by the isolation of a catalytically inactive allele from a screen for female sterile mutants, with the basis of that phenotype later being traced to defects in the piRNA pathway (Pane et al. 2007; Haase et al. 2010). Zucchini belongs to the phospholipase D (PLD) family of phosphodiesterases, which share a conserved catalytic motif, $\mathrm{HXKX}_{4} \mathrm{D}$ (Zhao et al. 1997).

The PLD family contains both phospholipases and nucleases, and Zucchini has long been viewed as a candidate process- ing enzyme for piRNA cluster transcripts (Siomi et al. 2011). Relatives of Zucchini, like the bacterial Nuc protein, cleave targets to leave $5^{\prime}$ phosphate and $3^{\prime}$ hydroxyl termini, just as one expects for a nuclease involved in piRNA biogenesis (Sasnauskas et al. 2010). The mouse homolog of Zucchini, PLD6, is also required for piRNA production (Huang et al. 2011; Watanabe et al. 2011). Yet, it has been reported to act as a phospholipase, converting a mitochondrial lipid, cardiolipin, to phosphatidic acid (PA) (Choi et al. 2006; Huang et al. 2011). This strongly pointed to a role for Zucchini in phospholipid production in vivo and, consequently, for a role of phospholipid signaling in the piRNA pathway.

To identify previously uncharacterized factors that contribute to primary piRNA biogenesis, we mined a collection of Drosophila EMS mutant strains that were previously annotated for sterility phenotypes (Wakimoto et al. 2004). From these, we identified 27 mutants, which also impacted transposon silencing. One displayed biochemical phenotypes that pointed to an impact on primary processing. We identified the mutation that caused this phenotype and found that it lay within the gene CG5508. CG5508 encodes a glycerol-3-phosphate O-acyltransferase (GPAT), which catalyzes a penultimate step in PA biosynthesis (Takeuchi and Reue 2009). CG5508 localizes to mitochondria and ER-like cisternae, which surround the nuage of Drosophila germ cells and is enriched at ring canals that form connections between nurse cells and the developing oocyte. CG5508 is partly colocalized with Zucchini on mitochondrial membranes, consistent with its acting at an early step in the primary piRNA biogenesis pathway.

The requirement for a GPAT in primary piRNA biogenesis strongly implicated PA in transposon silencing. Yet, mutations in the deeply conserved CG5508 active site did not impact its ability to support piRNA production. Moreover, biochemical evidence supports a role for Zucchini as a nuclease rather than as a phospholipase (Ipsaro et al. 2012; Nishimasu et al. 2012; Voigt et al. 2012). Thus, proteins that are involved in biosynthesis of PA appear to promote piRNA production independently of a possible role in phospholipid production. We have named CG5508 Minotaur (mino) to reflect its multicomponent nature and with reference to its position within the labyrinth of connections that support Drosophila oocyte development.

\section{RESULTS}

\section{A genetic screen for new primary piRNA components}

Unbiased genetic screens have proven a rich source of piRNA pathway components. In particular, mutations that lead to sterile phenotypes in flies are often associated with defects in transposon silencing via the piRNA pathway (Gillespie and Berg 1995; Wilson et al. 1996; Cook et al. 2004; Pane et al. 2007; Klattenhoff et al. 2009). These share a characteristic phenotypic signature with perturbation of dorsal-ventral 
and anterior-posterior axis specification and clearly observable alterations in dorsal appendage structures (Cook et al. 2004). In fact, such phenotypes have been used as a guide in targeted, smallscale searches for novel piRNA pathway components, particularly among Tudor domain-containing proteins (Klattenhoff et al. 2009; Zamparini et al. 2011; Zhang et al. 2011). We wished to build upon these insights in a broader search for proteins that act in the piRNA pathway, particularly with the hope of discovering new factors that promote primary piRNA biogenesis.

Toward this end, we took advantage of an existing collection of heavily EMSmutagenized Drosophila strains which carry lesions on chromosomes II and III, roughly 6000 strains per chromosome (Koundakjian et al. 2004). At the time the collection was produced, these were expected to average five to six nonsynonymous genic mutations per strain. Prior work annotated this collection for male and female sterility (Wakimoto et al. 2004; B Wakimoto, unpubl.) and identified $\sim 750$ candidate lines that were female and male sterile, with $\sim 500$ viable and obtainable by us. We took a multistep strategy to filter these for lines with defects in the piRNA pathway (Fig. 1A).

As a first step, we collected homozygous mutant animals and screened these for loss of transposon control using qPCR as an assay. Of the strains that we obtained, only $\sim 40 \%$ still yielded homozygous-viable animals, likely due to an accumulation of secondary mutations in the more than a decade during which these lines have been maintained in the presence of the balancer chromosomes. We tested the relative expression of transposable elements generally active only in somatic follicle cells (i.e., gypsy), of transposons predominantly active in germ cells (TART-A and GATE) and of an element active in both compartments (blood). We found 27 lines, 12 for chromosome II and 15 for chromosome III, that derepressed one or more of the elements tested to varying degrees (see Supplemental Information). Among these, five lines were found to harbor mutations in known piRNA genes, specifically in aub, armi, zuc, spn-E, and krimp (data not shown).

Loss of transposon silencing could result from impacts on the piRNA pathway at any of a number of steps. Altered

B
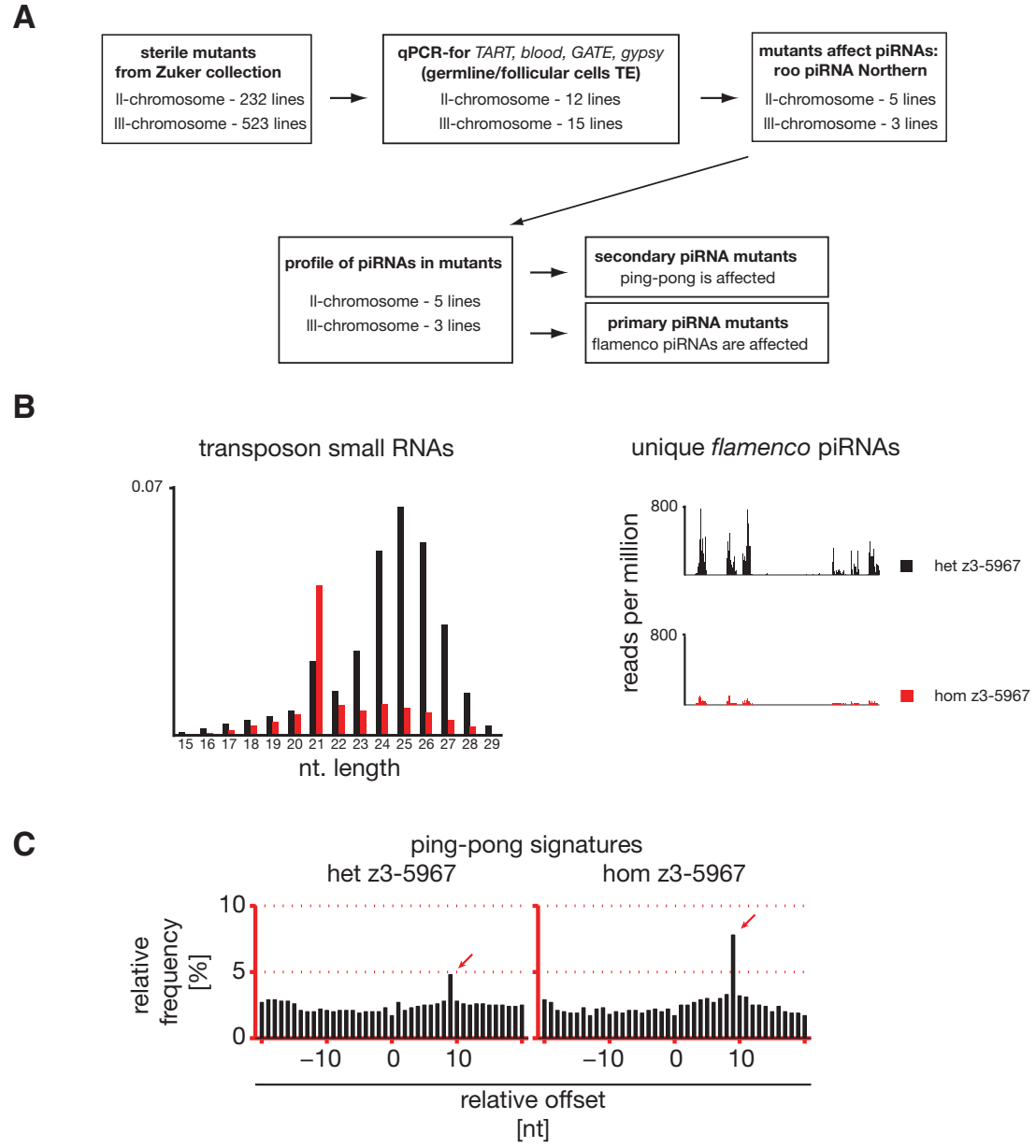

abundance of sense piRNAs

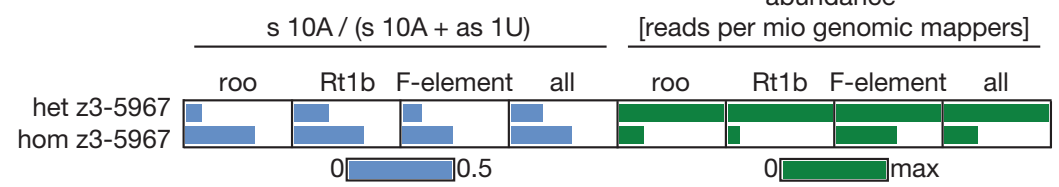

FIGURE 1. Mining the Zuker collection for piRNA pathway mutants. (A) A schematic representation of the screen of the Zuker collection is shown. (B) For z3-5967, analysis of global piRNA profiles was carried out using small RNA sequencing. To the left are size profiles of small RNAs that could be mapped to transposon consensus sequences for the heterozygous (black) and homozygous (red) animals normalized based upon the total number of mappers. To the right are similarly color-coded plots of piRNAs uniquely mappable to the flamenco piRNA cluster. $(C)$ Analysis of ping-pong signatures for z3-5967 heterozygous and homozygous females is shown (top). The peak indicated with the arrow highlights pairs with a 10-nt overlap, characteristic of ping-pong partners. (Bottom) Sense piRNAs, as a fraction of sense plus antisense, for three representative elements and all transposon mapping piRNAs (blue) and the overall abundance of all piRNAs (green) in heterozygous and homozygous ovaries.

piRNA populations could result from primary piRNA biogenesis or the ping-pong cycle (in germ cells). Alternatively, in cases with normal piRNA production, the ability of PIWI proteins to recognize and silence targets could be affected. To discriminate among these possibilities and to focus our efforts on novel piRNA biogenesis factors, we annotated these strains for impacts on piRNA levels, initially by Northern blotting (data not shown). Several strains showed reduced 
levels of selected piRNAs derived from the roo transposable element. These lines were further characterized by sequencing of piRNA populations. Among these, z3-5967 showed a strong overall reduction in piRNAs, as indicated by a shift in small RNAs corresponding to transposons toward the 21-nt size characteristic of endogenous siRNAs (Fig. 1B). Primary piRNAs derived from the somatic piRNA clusters, flamenco, were almost completely eliminated. A subset of the piRNAs that remained in the z3-5967 strain showed characteristics of secondary piRNAs, specifically enrichment for an $\mathrm{A}$ at position 10 of sense-oriented small RNAs, and a tendency for sense and antisense species to overlap by $10 \mathrm{nt}$ (Fig. 1C). These RNAs may have arisen from amplification of maternally deposited piRNA populations via the ping-pong cycle in germ cells (Brennecke et al. 2008). Of note, sense piRNAs were enriched in this mutant (Fig. 1C), perhaps due the increased availability of substrate for their production the following derepression of normally silent transposon copies. Similar effects have been noted upon mutation of essential components of the mammalian piRNA pathway (Aravin et al. 2008). Considered together, our data provoke the hypothesis that z3-5967 contains a mutation that affects primary piRNA biogenesis in both germ cells and follicle cells.

\section{z3-5967 harbors a mutation affecting primary piRNA biogenesis}

Given the potential for z3-5967 to harbor a mutation in a previously unrecognized piRNA biogenesis factor, we characterized the molecular phenotype of this strain in more detail. We began a broader examination of transposon derepression using both RNA-seq and qPCR. Transcriptome analyses, comparing z3-5967 homozygous females with their heterozygous siblings, revealed substantial increases in the expression of all classes of elements. These included those predominantly expressed in somatic follicle cells (e.g., mdg1, gtwin, gypsy family members), elements mainly expressed in germ cells (e.g., HeT-A, I-element) and those silenced by both branches of the piRNA pathway (e.g., blood, idefix) (Fig. 2A). These results were corroborated by $\mathrm{qPCR}$, though in some cases the two methods indicated different magnitudes of increased expression (Fig. 2B). Among protein coding genes, 48 showed statistically significant changes in expression, with 30 being increased and 18 decreased (Supplemental Table S1). The most plausible explanation is that these are altered as a secondary effect of defects in ovarian development that occur as a result of piRNA pathway lesions.

Zucchini has been ascribed a role in primary piRNA biogenesis because its loss not only affects mature piRNA levels, but also results in accumulation of long RNAs derived from piRNA clusters (Haase et al. 2010). In z3-5967 homozygotes, RNA-seq showed a statistically significant accumulation of long RNAs corresponding to the major piRNA clusters in the somatic (flamenco) and germline $(42 A B)$ lineages (Fig. $2 \mathrm{C}$ ). These observations were corroborated by qPCR, though the precise magnitudes of change observed varied between the two techniques (Fig. 2D).

$\mathrm{Yb}$ and Armitage, together with Vreteno, reside in cytoplasmic RNP structures, known as Yb bodies (Handler et al. 2011). In follicle cells, loss of $\mathrm{Yb}$ results in the disassembly of these structures, the delocalization of Vreteno and Armitage, and in a loss of primary piRNAs (Handler et al. 2011). In zuc mutants, the $\mathrm{Yb}$ body still forms, but its morphology is altered so that it appears larger and more diffuse (Handler et al. 2011; Saito et al. 2011). Z3-5967 homozygous animals formed $\mathrm{Yb}$ bodies that also showed these morphological changes as compared with heterozygous controls (Supplemental Fig. S1).

Mutations, which affect primary piRNA production, result in the loss of small RNA partners for Piwi. This in turn causes loss of its nuclear localization and a decrease in Piwi protein stability (Haase et al. 2010; Saito et al. 2011). Just as in $z u c$, armi, or vret mutants, Piwi was not detected in either germ or follicle cell nuclei of z3-5967 homozygotes (Fig. 2E). This correlated with a reduction in Piwi protein in ovaries (Fig. $2 \mathrm{~F}$ ), though the expression level of its RNA did not change (data not shown).

Defects in primary piRNA biogenesis correlate with loss of the characteristic nuage localization of Aubergine and Ago3. For example, in $z u c$ and vret mutants, Aubergine and Ago3 appear in dispersed cytoplasmic foci rather then in their normal perinuclear pattern (Olivieri et al. 2010; Handler et al. 2011). This phenotype was also observed in z3-5967 homozygous animals (Fig. 2E).

Surprisingly, we detected an increase in Ago3 protein levels in the z3-5967 homozygotes (Fig. 2F). Although the biochemical basis of this observation is unclear, elevated Ago3 levels correlate with the relative increase in sense piRNA species produced via the ping-pong cycle (Fig. 1C). Similar effects on sense piRNA species are seen with several piRNA biogenesis mutants, such as zuc and armi (Supplemental Fig. S2), supporting the generality of this phenomenon (Handler et al. 2011).

Considered together, these data suggest that z3-5967 harbors a mutation in a factor critical for primary piRNA biogenesis. Its molecular phenotype places the action of that factor near the top of the piRNA biogenesis pathway, downstream from piRNA cluster expression and near the step at which Zucchini acts.

\section{A causative mutation in CG5508, a glycerol-3- phosphate O-acyltransferase (GPAT)}

We used a recombinational mapping strategy to localize the causative mutation in z3-5967 with two assays, sterility and increased transposon expression measured by qPCR serving as readouts (Fig. 3A). This approach identified two distinct regions in the strain that caused sterility when present in a homozygous state. One of these, on the right arm of chromosome III, also harbored a mutation that derepressed transposons. This interval between $e$ (3R:17,062,900 bp) and $c a$ 
A

transposons (RNAseq)

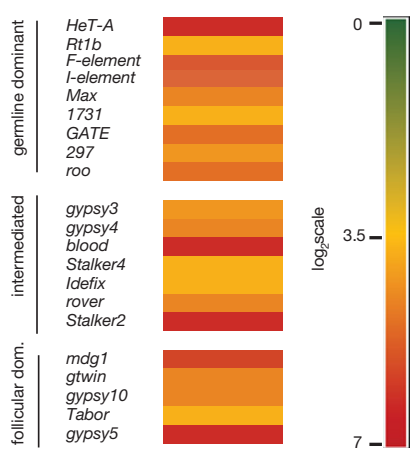

B
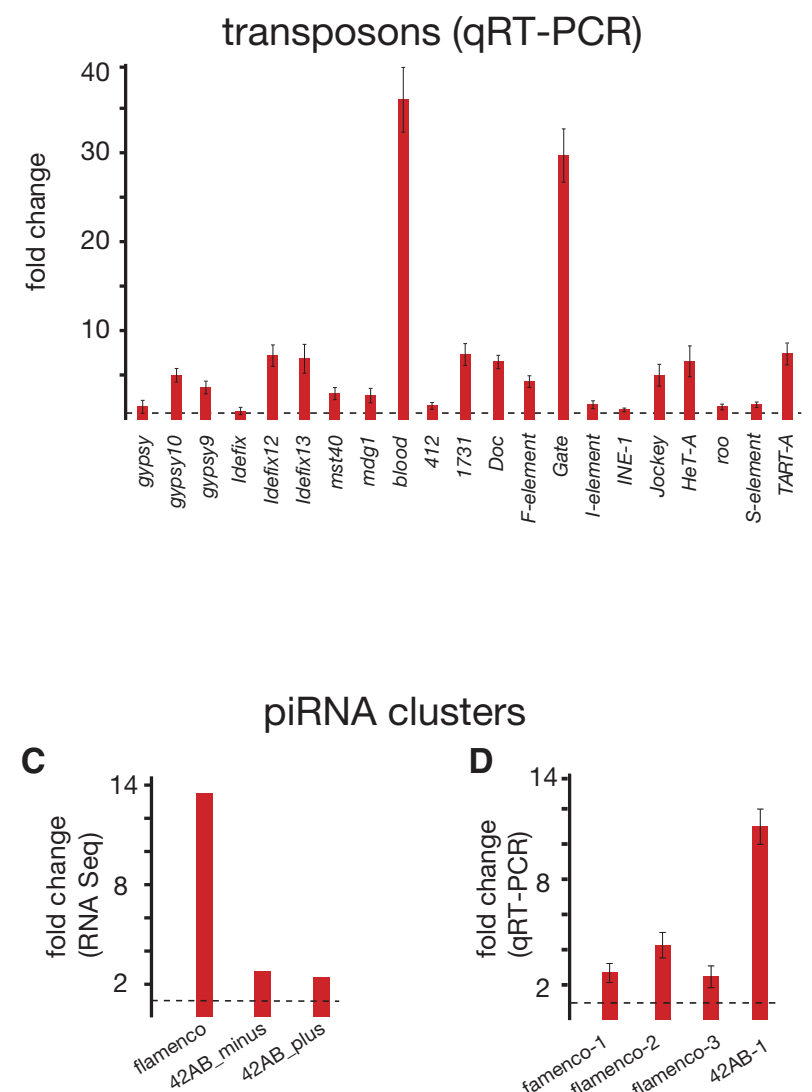

E

\section{PIWI family protein localization}

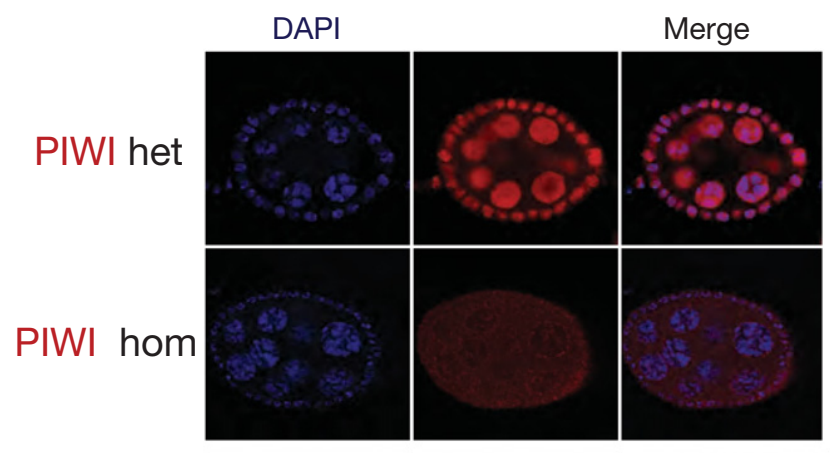

Aub het
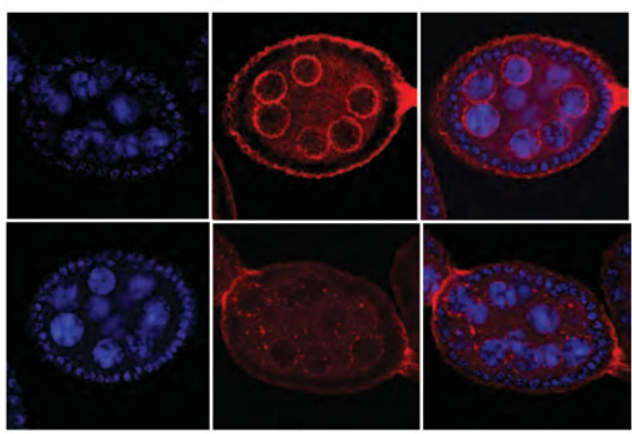

Ago3 het
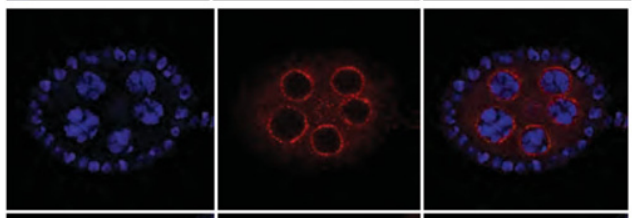

Ago3 hom
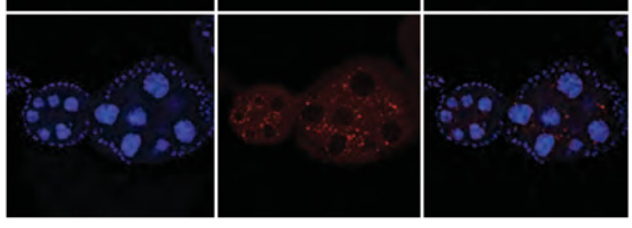

F

PIWI family protein expression

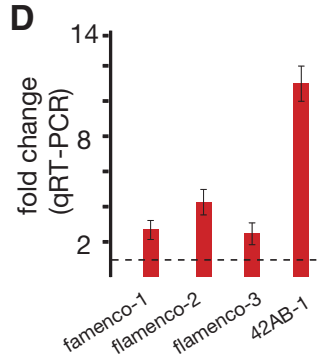

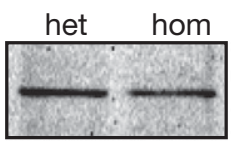

Tub

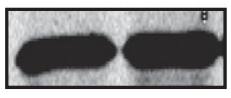

PIWI

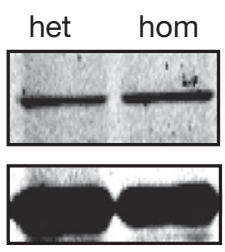

AUB
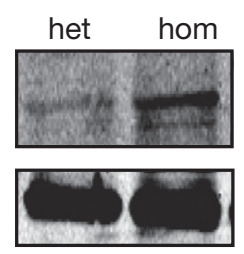

AGO3

FIGURE 2. Characterization of the piRNA pathway defects in z3-5967. (A) Transposon expression was analyzed in RNA-seq libraries from ovaries of z3-5967 homozygous and heterozygous animals using the DESeq package, and expression ratios were computed. Differential expression of selected transposons, representing classes that show somatic, germline, or mixed expression is presented as a heatmap with the scale on the right. (B) Relative expression of selected transposons in homozygous mutant animals, as compared with heterozygous controls, was measured by qRT-PCR. (C) The relative abundance of long RNAs, presumably corresponding to piRNA cluster transcripts, was quantified in RNA-seq libraries using DESeq. Fold changes in the homozygous mutants compared with the heterozygous siblings are shown. $P$-values associated with each fold change are as follows: flamenco, $2.18 \times \mathrm{e}^{-18} ; 42 A B$ minus strand, $0.0054 ; 42 A B$ plus strand, 0.0571 . $(D)$ Relative expression of the flamenco and $42 A B$ piRNA clusters in homozygous vs. heterozygous animals were measured using qRT-PCR with three probe sets for flamenco and one for $42 A B$. $(E)$ Localization of Piwi, Aubergine, and Ago3 was determined in homozygous and heterozygous animals, as indicated, using immunofluorescence with antibodies to the endogenous proteins. Staining is shown for stages 5/6 follicles. $(F)$ Levels of Piwi, Aubergine, and Ago3 in heterozygous and homozygous animals were determined by Western blotting. 
A

recombinational mapping

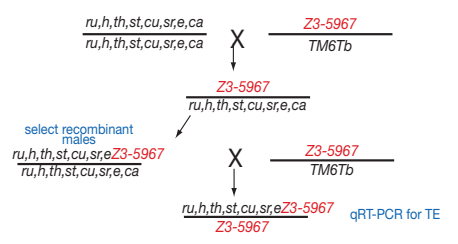

B

deficiency mapping of the causative mutation

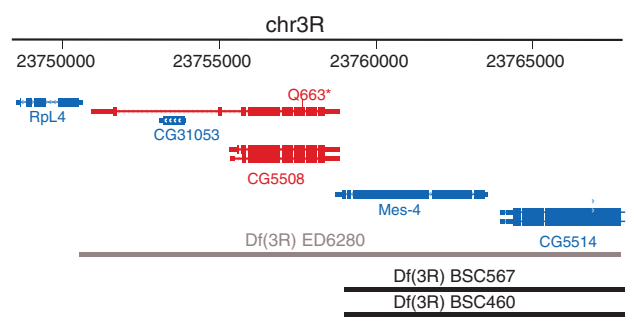

C

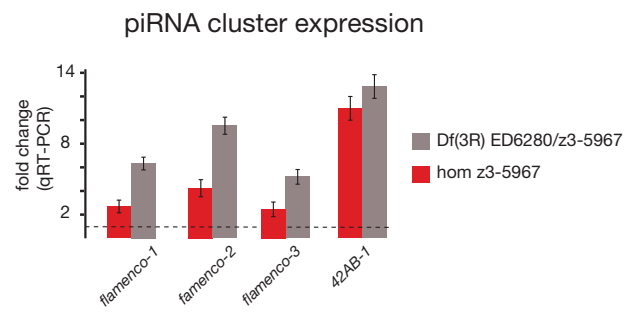

D

Transposon and flamenco expression in CG5508 KD flies

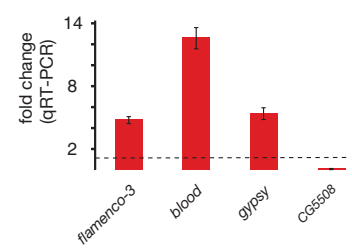

E

\section{localization in CG5508 KD cells}

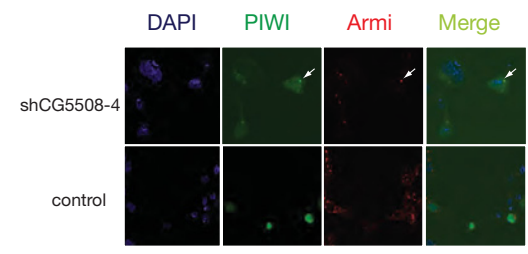

$\mathbf{F}$

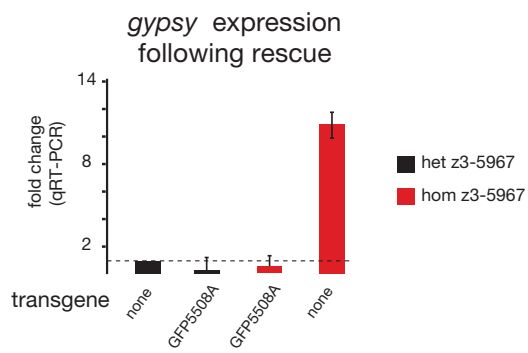

G

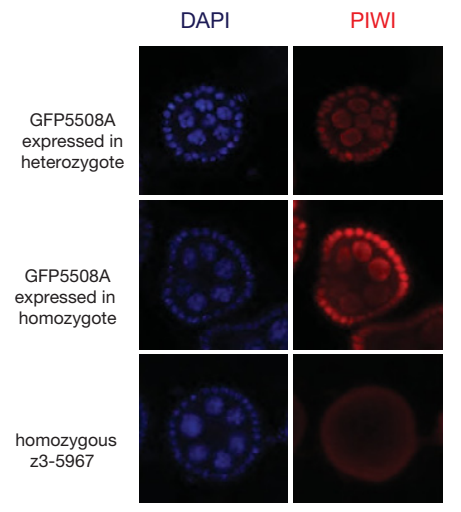

FIGURE 3. The causative mutation in z3-5967 resides in CG5508. (A) The scheme used for mapping the causative mutation in z3-5967 is shown. (B) Displayed is a diagram of the CG5508 genomic region showing candidate genes, structure of predicted splicing isoforms, regions deleted in deficiency chromosomes, and the location of CG5508 Q663* mutation. (C) Levels of presumed piRNA precursor transcripts for flamenco (three probe sets) and $42 A B$ were quantified in the z3-5967 homozygotes and in z3-5967/Df(3R)ED6280 hemizygotes. Fold change is relative to the z3-9567 heterozygote normalized to the levels of RP49. (D) Relative expression of the flamenco piRNA cluster and the blood and gypsy transposable elements was determined in flies expressing an RNAi construct directed against CG5508. A qRT-PCR of CG5508 is shown to verify the knockdown. In all cases ratios are calculated in comparison to control OSS cells. $(E)$ Localizations of Piwi and Armi were determined by immunofluorescence in OSS cells transfected with an siRNA against CG5508. The arrows indicate representative Yb bodies. (F) Relative expression of gypsy was determined by qRT-PCR in the z3-5967 mutant and homozygous strains expressing CG5508A isoform under the control of the ubiquitin promoter as compared with the indicated controls. $(G)$ Piwi localization was determined by immunofluorescence in z3-5967 heterozygotes and homozygotes expressing CG5508A from the ubiquitin promoter. Staining of stages $4 / 5$ follicles is shown.

(3R:25,632,970 bp) was used to refine the location of the causative lesion using deficiency chromosomes (Fig. 3B). One deletion $\operatorname{Df}(3 \mathrm{R})$ ED6280 was particularly informative: While it removed only a $12.7-\mathrm{kb}$ region (3R:23,750,857$23,774,482)$, hemizygous animals showed an even stronger phenotype than z3-5967 homozygotes. Hemizygous females were sterile and showed a substantial accumulation of piRNA cluster transcripts (Fig. 3C) as well as potent transposon derepression (Supplemental Fig. S3). The region deleted by Df(3R) ED6280 contained only four annotated genes, Mes-4, 
CG5508, CG5514, and CG31053. Two additional deficiencies that deleted both Mes-4 and CG5514 did not produce sterility or transposon derepression when heterozygous with the z35967 chromosome, arguing against either gene being responsible for the phenotype (data not shown).

To distinguish between CG5508 and CG31053, we examined these genes in a complete genomic sequence of z3-5967 homozygotes and searched for variants by comparison to the consensus genome and to complete genomic sequences of other Zuker collection strains. One variant in CG5508 stood out in the z3-5967 strain, a C-T change at 3R:23,757,700, which results in the introduction of a premature stop codon in place of a glutamate (Q663*) (Fig. 3B). Since this mutation was upstream of several splice sites, it had the potential not only to trigger protein truncation, but also to cause nonsense-mediated decay of the CG5508 mRNA. In accord with this notion, CG5508 transcript levels were reduced by 10 fold or threefold in the ovaries of mutant animals as measured by qPCR or RNA-seq, respectively (Supplemental Table S2; data not shown). These data strongly support the notion that a mutation within CG5508 led to the impact on the piRNA pathway that we observe in the z3-5967 strain.

To gain additional support for our hypothesis, we obtained publicly available P-element or piggyBac insertions near CG5508 from the Bloomington or Exelixis collections. None affected CG5508 expression and all were fertile as homozygotes (data not shown). As an alternative, we used RNAi to knockdown CG5508 in follicle cells. We expressed a CG5508 dsRNA using a follicle cell-specific tj-GAL4 driver and observed derepression of transposons (e.g., blood and gypsy) and an increase in the accumulation of long RNAs from the flamenco cluster (Fig. 3D). In contrast, knockdown of Mes-4 or CG31053 using a similar strategy had no impact on these readouts (data not shown). We also detected dramatic gypsy derepression upon knockdown of CG5508 by introduction of specific siRNAs into cultured ovarian somatic sheet (OSS) cells. These cells also showed a loss of Piwi in the nucleus and its accumulation in $\mathrm{Yb}$ bodies (Fig. 3E).

The CG5508 gene expresses at least three isoforms in ovaries, annotated as RA, RB, and RC. These have different amino termini but share the majority of their coding potential (Supplemental Fig. S4). Of these, only isoform A contains a predicted transmembrane domain, whereas the other two variants do not. We created transgenic flies in which the ubiquitin promoter was used to drive the expression of the A or C isoforms fused to GFP or RFP at either their amino or carboxyl termini, respectively. Expression of either an amino-terminal GFP fusion to the A isoform (Ubi > GFP-CG5508A) or a C-terminal RFP fusion to the $\mathrm{C}$ isoform (Ubi > CG5508C-RFP) restored fertility, transposon silencing, and Piwi localization in z3-5967 homozygous flies (A isoform; Fig. 3F,G; C isoform, data not shown). We do not currently understand whether there are functional differences among CG5508 isoforms.

Considered together, our data strongly implicate CG5508 as a previously unrecognized component of the piRNA biogenesis machinery. CG5508 is a member of a highly conserved protein family of glycerol-3-phosphate O-acyltransferases (GPAT) (Supplemental Figs. S4, S5). These proteins convert glycerol-3-phosphate into lysophosphatidic acid, and CG5508 is proposed to act in flies to catalyze the penultimate step of phosphatidic acid biosynthesis. Given the well-established biochemical activity of this protein, we interpreted our results as a strong indication that phospholipid signaling might be critical for some aspect of primary piRNA processing.

\section{An intact CG5508 catalytic site is dispensable for piRNA biogenesis}

The mechanisms of PA production are generally well understood (Fig. 4A). Two key primary piRNA biogenesis factors fit directly into these pathways and are proposed to promote the synthesis of this phospholipid. To investigate the possibility that PA in some way regulates primary piRNA processing, we systematically knocked down genes expected to affect PA levels in follicle cells using tj-GAL4 to drive the expression of pValium20-encoded shRNAs against phospholipid biosynthesis genes (Fig. 4B; Ni et al. 2011). With the exceptions of CG5508 and Zucchini, none of our individual knockdowns caused increases in transposon expression. We also doubly knocked down the two potentially redundant 1-acyl-sn-glycerol-3-phospahte acyltransferases (AGPATs; CG4753 and CG4729), which act directly downstream from CG5508 to convert monoacyl-glycerol-3-phosphate to PA. These animals did show a dramatic reduction in ovary size (Supplemental Fig. S6) and were infertile, perhaps due to disruptions in phospholipid signaling; however, they did not show a significant increase in transposon expression (Fig. 4B). We saw consistent results in studies carried out in cultured OSS cells (Fig. 4C) and fly germ cells (data not shown), namely, that the only two proteins associated with PA synthesis that affected transposon silencing were Zucchini and CG5508. This led us to question whether a role for CG5508 in PA production was linked to effects on the piRNA pathway.

The active site of GPATs is deeply conserved and consists of four motifs (Fig. 4D; Supplemental Figs. S4, S5). Motif 1 contains a sequence $\mathrm{HX}_{4} \mathrm{D}$ that is invariant in active enzymes. Changing the histidine to alanine in a bacterial GPAT (plsB) completely abolishes the activity of the enzyme, whereas converting the aspartate to glutamate reduces activity by 10 -fold (Heath and Rock 1998). We introduced both changes into the catalytic site of a construct that drives the expression of a C-terminal fusion between the CG5508 C isoform and RFP from the ubiquitin promoter. These were used to create transgenic animals in order to assess whether our fusion proteins would rescue the mutant phenotype. Both the intact and catalytic mutant (termed CD) transgenes fully rescued transposon silencing and Piwi nuclear localization in the z3-5967 strain (Fig. 4E,F). 
A

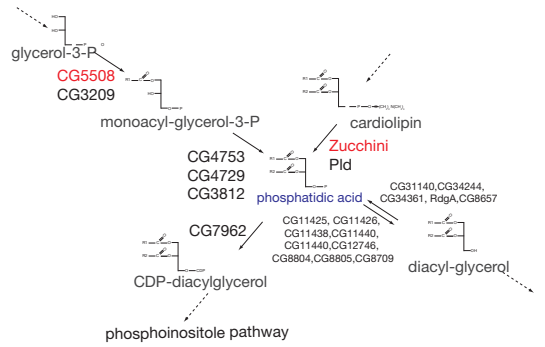

B

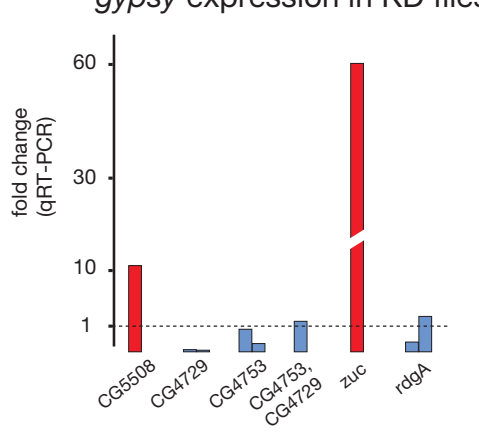

C

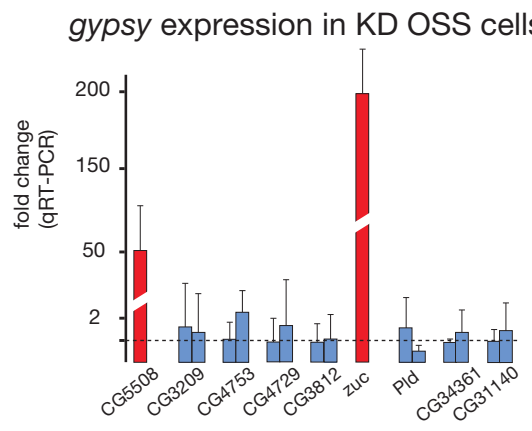

D

Phosphate acyltransferase motifs

\begin{tabular}{|c|c|}
\hline $\begin{array}{l}\text { CG5508 (NP_651597.1) } \\
\text { D. melanogaster }\end{array}$ & LIFVPLH \\
\hline $\begin{array}{l}\text { CG5508cd (NP_651597.1) } \\
\text {. melanogaster }\end{array}$ & LIFVP \\
\hline $\begin{array}{l}\text { PlsB(EDX31343) } \\
\text { E. coli }\end{array}$ & \\
\hline $\begin{array}{l}\text { mGPAT2 (NP_001074558.1) } \\
\text { M. musculus }\end{array}$ & LVFLS \\
\hline $\begin{array}{l}\text { droGPAM (XP_002664023) } \\
\text { D. rerio }\end{array}$ & \\
\hline & \\
\hline $\begin{array}{l}\text { G3209_C(AAF47157) } \\
\text { melanogaster }\end{array}$ & \\
\hline
\end{tabular}

E

gypsy expression in CD rescue flies

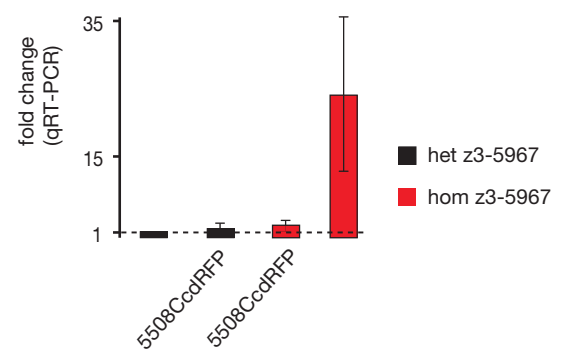

$\mathbf{F}$

PIWI localization in CD rescue flies

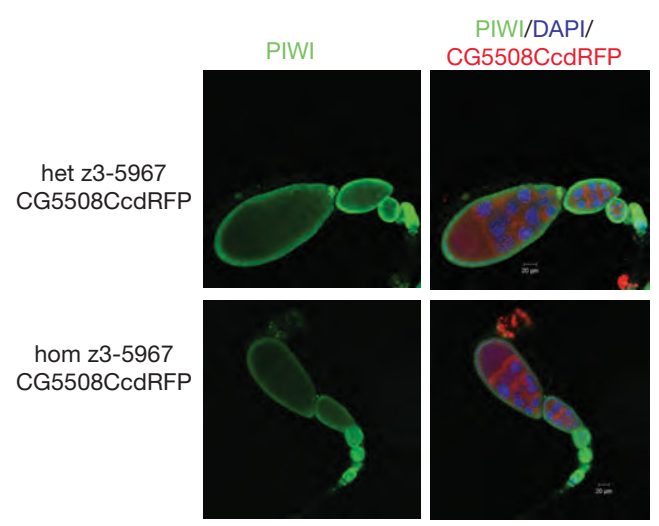

FIGURE 4. The GPAT activity of CG5508 is not required for its function in the piRNA pathway. (A) A general scheme of the Drosophila PA biosynthesis pathway is shown with its annotated components. Proteins linked to the piRNA pathway are shown in red. (B) Effects on gypsy expression were measured by qRT-PCR in flies engineered to express shRNAs targeting the indicated elements of the PA biosynthesis pathway in follicle cells (Valium20-encoded shRNA combined with a tj-Gal4 driver). Red bars indicate known piRNA pathway components and instances where two bars are associated with a given gene indicate results from two independent shRNAs. $(C)$ Effects of knockdowns of PA biosynthesis components on gypsy expression were assessed as in $B$, except that cultured OSS cells were transfected with siRNAs against the indicated genes. Again, multiple bars indicate results from different siRNA knockdowns. $(D)$ Alignments are shown for GPAT catalytic residues of the selected CG5508 homologs from different organisms. Residues shown in red indicate those altered in CG5508 to render it inactive, which presumably negate the activity of zebrafish GPAT2 (see Supplemental Figs. S5, S7). (E) Relative expression of gypsy was measured by qRT-PCR in homozygous or heterozygous mutants with or without enforced expression of the catalytically inactive CG5508 isoform C, as indicated. (F) Homozygous or heterozygous mutants expressing catalytically inactive CG5508 isoform C were tested for Piwi localization.

It is worth noting that the stop codon created by the EMSinduced mutation in CG5508 creates a C-terminal truncation. Though this remains to be tested, the truncation has the potential to produce a fully functional GPAT, at least based upon comparisons of CG5508 to known GPAT structures. Moreover, the closest relative of CG5508 in zebrafish, droGPAT2, harbors a natural variant in the active site that changes the critical histidine to arginine (Fig. 4D). Thus, 
considering biochemical, genetic, and evolutionary evidence, our results point to a role for CG5508 in the piRNA pathway that is independent of any ability to promote the synthesis of PA.

\section{CG5508 is found on mitochondria, ER, and at ring canals}

The mouse genome encodes four GPATs. GPAT3 and GPAT4 have been shown to localize the ER, whereas GPAT1 and GPAT2 were found on the outer mitochondrial membrane. The Drosophila genome, in contrast, encodes two GPATs. CG5508, which is more closely related to GPAT1 and GPAT2 from mouse and CG3209, which is more similar to GPAT3 and GPAT4 (Supplemental Fig. S7). We sought to gain insight into the roles of CG5508 by determining its localization. Fusion proteins with the CG5508 A and C isoforms largely colocalized throughout all stages of ovariole development when their expression was driven from a ubiquitously active promoter. Isoform $\mathrm{C}$ was somewhat concentrated in prominent cytoplasmic foci from stages 7 to 10 (Fig. 5A; data not shown). Both the $\mathrm{N}$ - and C-terminal RFP fusions to the $\mathrm{C}$ isoform were used to decipher the relative intracellular localization of CG5508 with reference to ER and mitochondrial membranes, which were individually tagged with YFP. Both fusions were found in proximity to the mitochondria and ER, and sometimes form a curious crown-like focus near nurse cell nuclei (Fig. 5B). A similar pattern was observed for catalytically inactive mutant versions of isoforms A and C (Supplemental Fig. S8).

The ER and mitochondria are parts of a membranous network called the fusome. This highly condensed vesicular structure connects all 15 nurse cells in a syncytium and is used to transport RNA and protein into the growing oocyte. Fusome membranes associate with the cytoskeleton and can be marked by the adducin homolog, Hu-li tao shao (hts), and F-actin (Morawe et al. 2011). The connections between cells are known as ring canals and are formed from incomplete cleavage furrows during early egg chamber development. Foci of CG5508 are found adjacent to and sometimes within ring canals, marking CG5508 as a new component of the labyrinthine fusome network (Fig. 5C). Considering this localization and the multicomponent nature of CG5508 as a potential GPAT and bona fide piRNA biogenesis factor, we have named this protein Minotaur (Mino). The mutant minotaur gene in z3-5967 harbors a stop codon that is predicted to affect all isoforms, but lies at Q663 of isoform A. We therefore termed this mutant allele minotaur ${ }^{\text {Q663* }}$.

\section{Relative localization of Minotaur and known piRNA pathway components}

Given its role in the piRNA pathway, we asked whether Minotaur could be found in proximity to well-established components of the piRNA pathway. We did not observe over-
A

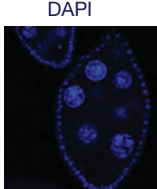

ubiGFP5508A
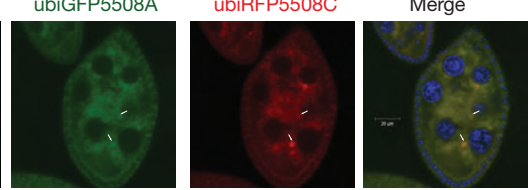

B
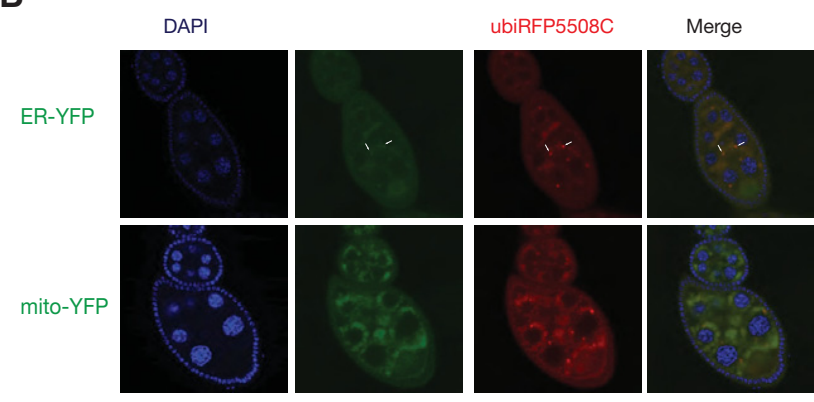

C
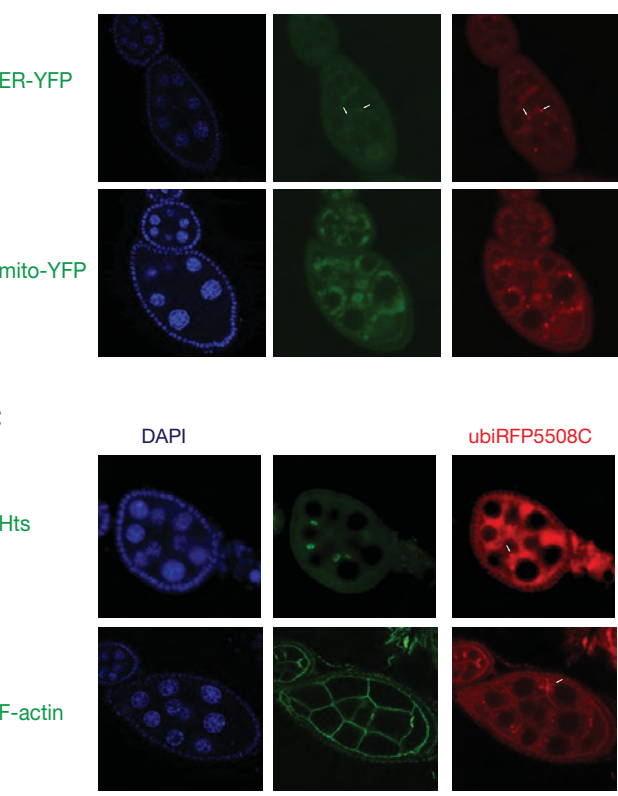

ubiRFP5508C
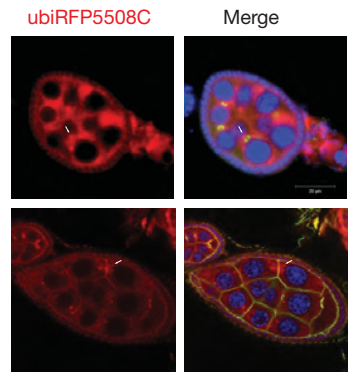

FIGURE 5. Subcellular localization of CG5508. (A) Shown are images of stage 8 follicles from animals coexpressing fluorescently tagged CG5508 isoforms A (GFP) and C (RFP). (B) The localization of isoform $\mathrm{C}$ (RFP) is shown in comparison to endoplasmic reticulum (ER-YFP, top) or mitochondria (mito-YFP, bottom) in stages 6/7 follicles. Arrows indicate areas of relatively high CG5508 concentration. (C) The localization of isoform C (RFP) is shown in comparison to markers of ring canals (Hts, top; F-actin, bottom).

lap between Minotaur and known nuage components, including Armitage, Aubergine, Vasa, and Ago3 (Fig. 6A). Armitage, which has been proposed to localize partially to the sponge body (Handler et al. 2011), partially overlapped with Minotaur during early stages of oocyte development (Fig. 6A). Minotaur did not colocalize with Armitage in follicle cells nor did its localization overlap with $\mathrm{Yb}$, indicating that it is not a component of the $\mathrm{Yb}$ body (data not shown). We did note substantial colocalization of the GFP-tagged A isoform with a Zucchini-RFP fusion protein. These proteins colocalized throughout ovariole development and in follicle cells, with both showing slightly elevated expression in germline stem cells (Fig. 6B-F). Additionally, both form foci at ring canals (data not shown). These findings are consistent with our molecular data, suggesting action at a similar step of piRNA biogenesis. Considering both genetic evidence and the overlapping localization patterns of Zucchini and Minotaur, we propose that Minotaur collaborates with Zucchini in primary piRNA processing near the mitochondrial membrane. 
A

B

C

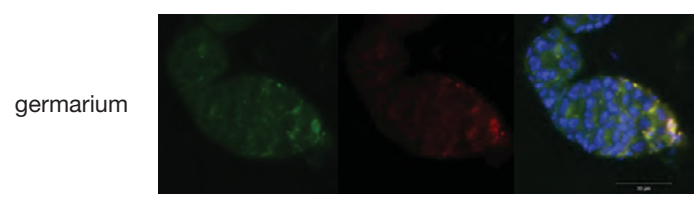

D

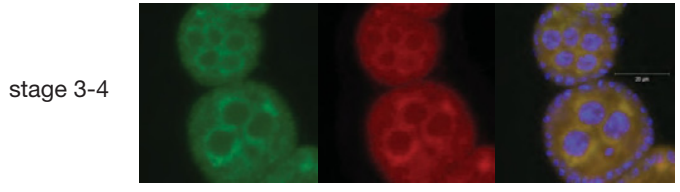

$\mathbf{E}$

stage 6-7

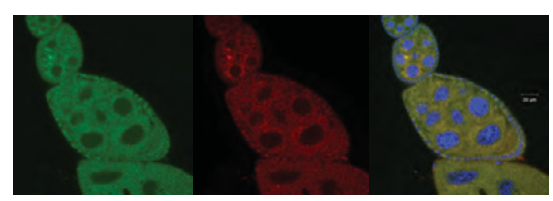

$\mathbf{F}$

follicular cells stage 9

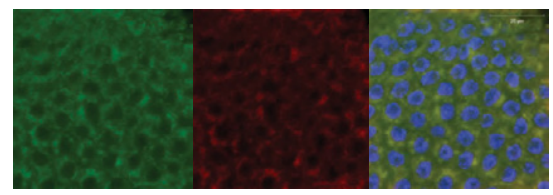

FIGURE 6. CG5508 is colocalized with Zucchini in both germline and follicular cells. (A) CG5508 isoform A (GFP) is shown in relation to endogenous Aubergine (top) or Armitage (bottom). ( $B-F)$ The localization of CG5508 isoform A (GFP) is shown in comparison to the localization of Zucchini as a C-terminal RFP fusion protein. Stages of germ cell development and follicle cells are as indicated.

\section{DISCUSSION}

A combination of genetics, biochemistry, and cell biology approaches place Minotaur near the apex of the piRNA pathway, alongside Zucchini, with both proteins playing a role in primary piRNA biogenesis (Haase et al. 2010). These proteins appear to act upstream of proteins that localize to the $\mathrm{Yb}$ body, including $\mathrm{Yb}$ itself, Armitage, and Vreteno. In turn, all of these act upstream of the Piwi proteins (Siomi et al.
2011). A combination of RNA-seq and qPCR implicate both Zucchini and Minotaur in the processing of primary piRNA cluster transcripts since these accumulate only in those mutants, but not in animals or cells with defects in at least some $\mathrm{Yb}$ body components (Haase et al. 2010; Zamparini et al. 2011).

A number of additional characteristics link Minotaur and Zucchini. Both are found on membranous organelles. Minotaur is found on both mitochondrial and ER membranes, whereas Zucchini has been mainly seen in association with mitochondria (Saito et al. 2009). Though higher resolution imaging is needed, we do see substantial colocalization of Minotaur and Zucchini, particularly at the ring canals, which link the nurse cells and the oocyte in a continuous syncytium in the developing egg chamber. The presence of Minotaur along the labyrinthine membranous network, the fusome, which functions to deliver RNAs and proteins to the developing oocyte, is provocative. It is clear that oocytes accumulate and store both piRNAs and Piwi proteins, and the concentration of these in the pole plasm is likely important for the transmission of epigenetic information about transposon challenges from mothers to progeny (Brennecke et al. 2008). It is tempting to speculate that the presence of both Minotaur and Zucchini specifically at junctions between cells and on the transport network that feeds oocytes might be critical to this process of small RNA-based inheritance. In this way, the activity of a transposon in even a single nurse cell could be communicated to the next generation via this network.

Another interesting and notable link between Minotaur and Zucchini is that both are proposed to act in pathways that lead to the biosynthesis of PA (Takeuchi and Reue 2009; Huang et al. 2011). Yet, for Minotaur this function is dispensable for its action in the piRNA pathway. Whether Minotaur plays an important role in PA synthesis independently of its function in piRNA biogenesis is unknown. We have found that monoacyl phosphoglycerol derivates that would be produced by Minotaur are not affected in mutant animals (data not shown), though the presence of a potentially redundant GPAT could confound this analysis. Unlike Minotaur, Zucchini depends upon the integrity of its phospholipase active site to support piRNA biogenesis (Haase et al. 2010). However, recent structural and biochemical studies point more strongly to its action as a single-strand-specific nuclease rather than as a phospholipase to promote primary piRNA biogenesis (Ipsaro et al. 2012; Nishimasu et al. 2012; Voigt et al. 2012). It is unclear why components of lipid biosynthesis pathways, some of which belong to deeply conserved enzyme families, might have been coopted for functions in transposon silencing. The concentration of Zucchini and Minotaur on mitochondrial membranes might have ancient links to the initially unexpected roles that mitochondria are now known to play in antiviral responses and in regulating programmed cell death (Tal and Iwasaki 2011). However, there is no obvious proximate link between PA and either of these processes, 
though signals downstream from PA can regulate cell survival (Tal and Iwasaki 2011).

Like many proteins that function within the piRNA pathway, the precise biochemical role played by Minotaur is unclear. Phylogenetic analysis has revealed that multicellular organisms encode two types of GPAT enzymes. One class has just the core GPAT domain, while the other class bears a C-terminal extension with no annotated function. The truncating mutation in our Minotaur allele removes its $\mathrm{C}$ terminus, but leaves all structural motifs that constitute the core GPAT intact. Using secondary structure prediction algorithms (Phyre2) to probe the nature of the C-terminal domain (Kelley and Sternberg 2009), we uncovered a simple winged-helix motif that might provide nucleic acid-binding capacity (Supplemental Fig. S9); however, at the moment this must be considered pure speculation. Interestingly, Acaridae, which lack piRNAs, do not have a GPAT family member with a strongly predicted C-terminal winged-helix motif. It is therefore tempting to propose that Minotaur might interact in some way with piRNA precursor transcripts to facilitate their processing, a hypothesis that must now be tested biochemically.

\section{MATERIALS AND METHODS}

\section{Fly stocks}

Fly stocks were maintained at $25^{\circ} \mathrm{C}$ in standard conditions. Stocks were obtained from the Bloomington, VDRC, Harvard, or Kyoto stock centers (Supplemental Table S3). Previously annotated sterile mutant fly lines, a subset of which showed transposon derepression (Supplemental Table S4), were obtained from the Zuker collection (Koundakjian et al. 2004).

\section{Phenotypic characterization of EMS mutant lines}

One to 3-day-old non-virgin female adults from the Zuker collection lines were sorted into heterozygous and homozygous groups and kept on yeast for 1-2 d to verify their sterility. Thereafter, 10-15 ovaries were manually dissected in $1 x P B S$ and RNA was extracted using TRIzol reagent (Invitrogen 15596-026) following the manufacturer's instructions. One microgram of RNA was treated with DNase I Amplification Grade (Invitrogen 18068015). Complementary DNA was prepared by reverse transcription using oligo $(\mathrm{dT}) 20$ primer and SuperScript III Reverse Transcriptase (Invitrogen 18080044). qPCR was carried out using SYBR Green PCR Master Mix (Applied Biosystems 4309155) a Chromo4 Real-Time PCR Detector (Bio $\mathrm{Rad}$ ). Transcripts were quantitated by the $\Delta \Delta \mathrm{C}(\mathrm{t})$ method (Livak and Schmittgen 2001) and normalized to transcript levels of a reference gene (rp49). At least two biological replicates were used to measure the expression of the following transposable elements: gypsy, blood, HeT-A, and GATE (for primers see Supplemental Table S5). Lines, which showed up-regulation in one or more transposable elements (more than 10-fold up-regulation) were used for further analysis. These mutants were analyzed by Northern blotting of ovary RNA for roo piRNA expression with a selected set of piRNA probes according to Vagin et al. (2006). Selected lines were used in comple- mentation crosses to eliminate known loci (see Supplemental Tables S3, S4 for strains).

\section{Small RNA cloning and analysis}

Small RNA cloning and analysis of small RNA libraries was done according to Brennecke et al. (2007) and Malone et al. (2009).

For ping-pong analysis, after mapping small RNA reads with up to two mismatches to the Drosophila melanogaster transposon consensus sequences, piRNAs were selected based on a length of $23 \mathrm{nt}$ or greater. Only reads with either a $\mathrm{U}$ at position $1, \mathrm{~A}$ at position 10 , or both, were used for further analysis. For each piRNA, the abundance of all neighboring piRNAs on the opposite strand within a certain window (20-nt upstream and 20-nt downstream) and their relative $5^{\prime}$ end distance was recorded. Every sequence could hereby account for multiple putative ping-pong pairs, but was only counted once per offset. After calculating the abundances for all windows over all transposons, the counts were summed up and displayed as percent relative to the window for each offset. For ping-pong analysis of piRNA population in zucchini, armitage, vreteno, and $\mathrm{Yb}$ mutants we use previously published Gene Expression Omnibus data no. GSE30955 (Handler et al. 2011).

\section{Transcriptome libraries and analysis}

Transcriptome libraries were prepared according to Armour et al. (2009) using not-so-random priming (NSR). Samples were sequenced on an Illumina Genome Analyzer II for 36 cycles in a single end-sequencing run. DESeq was used according to Anders and Huber (2010). Twenty-eight nucleotide reads were mapped to the Drosophila melanogaster genome assembly (BDGP release 5/dm3) with TopHat (v1.4.1) and a custom Bowtie index (Bowtie v0.12.8) based on Drosophila annotated transcripts from Flybase release dmel-r5.43 for genes, transposable elements, and a set of 20 piRNA clusters (Malone et al. 2009). We calculated read counts using bedtools (Quinlan and Hall 2010) and identified significantly differentially expressed $(P<0.10)$ candidates using DESeq v1.8.2 (Anders and Huber 2010).

\section{Whole genome sequencing}

A total of $500 \mathrm{ng}$ of genomic DNA from z3-5967 homozygous mutants was fragmented using a Bioruptor (Diagenode) in $10 \mathrm{mM}$ Tris- $\mathrm{HCl}$ ( $\mathrm{pH}$ 8.0). For end repair, phosphorylation, and adenylation of $3^{\prime}$ ends, $18.5 \mu \mathrm{L}$ of DNA was mixed with $2.5 \mu \mathrm{L}$ of $10 x$ T4 DNA Ligase Bfr with $10 \mathrm{mM}$ ATP (NEB cat \#B0202S), $1 \mu \mathrm{L}$ of dNTPs (10 mM each, Invitrogen), $1 \mu \mathrm{L}$ of T4 DNA Polymerase (NEB, $3000 \mathrm{U} / \mathrm{mL}$ ), $1 \mu \mathrm{L}$ of T4 PNK (NEB, 10,000 U/mL), and $1 \mu \mathrm{L}$ of Roche Standard Taq DNA Polymerase (5000 units/mL, cat \# 11 146165001 ) and incubated at $25^{\circ} \mathrm{C}$ for $20 \mathrm{~min}$, then at $72^{\circ} \mathrm{C}$ for $20 \mathrm{~min}$. Next, $1 \mu \mathrm{L}$ of $25 \mu \mathrm{M}$ pre-annealed, Illumina PE adapters and $1 \mu \mathrm{L}$ of Roche Rapid T4 DNA Ligase (5000 units/mL, cat \# 11635379001 ) were added and incubated for another $15 \mathrm{~min}$ at $25^{\circ} \mathrm{C}$. The adapter-ligated DNA was recovered on columns according to the manufacturer's protocol (Zymo Clean and Concentrator-5) and eluted in $10 \mu \mathrm{L}$ of preheated $\left(50^{\circ} \mathrm{C}\right) 10 \mathrm{mM}$ Tris- $\mathrm{HCl}$ ( $\mathrm{pH}$ 8.0). Two microliters of the eluate was used for enrichment PCR with Solexa PE primers PE1.0 and PE2.0 using Roche HiFi 
polymerase (Roche 11732641001 ). The sample was sequenced on a Solexa GA ll platform.

\section{Molecular cloning and production of transgenic flies}

Full-length coding sequences of CG5508A, CG5508B, CG5508C, and Zuc were amplified from Drosophila ovary cDNA (for primers see Supplemental Table S6), cloned into the pENTR/D-TOPO (Invitrogen K240020) vector according to the manufacturer's protocol, and recombined into N- or C-terminal GFP or RFP destination vectors under the control of ubiquitin promoter, from the Drosophila Gateway Collection (Terence Murphy, Carnegie Institute of Washington, and Clara Moch and Jean-Rene Huynh, Institute Jacques Monod, CNRS, University Paris) using Gateway LR Clonase Enzyme Mix (Invitrogen catalog \# 11791-019) according the manufacturer's protocol. The cDNAs of CG5508A and C encoding catalytically inactive isoforms were cloned by overlapping PCR. First we used primers CG5508-A-5' or CG5508-C-5' together with reverse CG5508 cat dead to amplify the $5^{\prime}$ end of CG5508; to amplify the $3^{\prime}$ end of CG5508, primers CG5508-A-3' no stop and forward CG5508 cat dead were used. After mixing the CG5508 PCR products representing the $5^{\prime}$ and $3^{\prime}$ end, the entire cDNA was amplified by PCR using CG5508-A-5' and CG5508-A-3' for isoform A and CG5508-C-5' and CG5508-A-3' for isoform C.

Cloning of shRNAs into $\mathrm{pValium-20}$ vector was done according to Ni et al. (2011) (for shRNA sequences see Supplemental Table S6).

CG5508 expression constructs were used to produce transgenic flies (Bestgene). Individual transgenic lines were double balanced to map chromosomal position of the insertion and used for rescue crosses. pValium-20 constructs were injected by Genetic Services, Inc. and integrated into attP2 and attP40 target sites.

\section{Antibodies, immunofluorescence, and Western blotting}

For immunofluorescence, fly ovaries were dissected in 1xPBS, fixed in $4 \%$ PFA (in 1xPBS) for $20 \mathrm{~min}$, washed twice with $1 \times$ PBS for 10 min each, permeabilized for $10 \mathrm{~min}$ in $0.1 \%$ TritonX100 (in $1 x$ PBS), washed twice in PBST $(0.1 \%$ Tween in $1 x P B S)$, blocked for $1 \mathrm{~h}$ in $1 \% \mathrm{BSA}$ (in 1xPBS), incubated with primary antibodies overnight at $4^{\circ} \mathrm{C}$, washed three times with PBST for 10 min each, and incubated with secondary antibodies $(2.5: 1000)$ at room temperature for $1 \mathrm{~h}$. Then ovaries were washed twice with PBST and incubated with DAPI (1:10000 in PBST) for $5 \mathrm{~min}$, washed for $1 \mathrm{~h}$ with PBST, and mounted in ProLong Gold Antifade Reagent (Invitrogen P36930). Images were acquired with a Zeiss 710 LSM Confocal microscope.

For colocalization of Zuc-RFP and CG5508A-GFP, all steps after the fixation and washes were skipped and nuclei were visualized with Hoechst 33342 (Sigma H3570).

To assay PIWI GFP fusion protein localization in OSS transfected cells, cells were fixed in 2\% Paraformaldehyde for $5 \mathrm{~min}$ and the remainder of the procedure was identical to ovary immunofluorescence protocol.

We used the following primary antibodies: mouse anti- $\mathrm{Yb}(1: 1000)$ (kind gift from Mikiko Siomi), rabbit anti-Armi (1:500) (kind gift from Bill Theurkauf), rabbit anti-zuc8 (1:250), rabbit anti-PIWI (1:500-1000), rabbit anti-Aub (1:500), Ago3 (1:250-500), all three described in Brennecke et al. (2007), phalloidin 488 (Invitrogen A12379) and phalloidin 568 (Invitrogen A12380) $(2 \mu \mathrm{g} / \mathrm{mL}$ ), and
anti-HtsR (1:50) (Developmental Studies Hybridoma Bank). The secondary antibodies were used at 2.5:1000 dilutions: anti-rabbit Alexa Fluor 488 (Invitrogen A11008), anti-rabbit Alexa Fluor 568 (Invitrogen A11011), anti-mouse Alexa Fluor 488 (Invitrogen A11001) and anti-mouse Alexa Fluor 568 (Invitrogen A21043).

For Western blot analysis we used rabbit anti-PIWI (1:500), rabbit anti-Aub (1:500) and rabbit anti-Ago3 (1:500), and visualized the samples using the Odyssey Western imaging system.

\section{OSS cell culture}

The OSS cell line was a kind gift from Yuzo Niki and was cultured as described (Niki et al. 2006; Haase et al. 2010). Cells were transfected using the Xfect reagent (Clontech) for DNA transfections according to the manufacturer's instructions (Haase et al. 2010) or the Amaxa Nucleofector for siRNA transfection as described in Saito et al. (2009). A list of the siRNAs used can be found in Supplemental Table S7.

\section{RNA isolation, reverse transcription, qPCR analysis}

For Figures 2-4, qPCR analysis was performed as follows. Total RNA from ovaries or OSS cells was extracted using TRIzol (Invitrogen 15596-026) according to the manufacturer's instructions. One microgram of RNA was treated with DNase I Amplification Grade (Invitrogen 18068015) according to the manufacturer's instructions. Complementary DNA was prepared by reverse transcription using oligo(dT) 20 primer and SuperScript III Reverse Transcriptase (Invitrogen 18080044). qPCR was carried out using SYBR Green PCR Master Mix (Applied Biosystems 4309155) and primers (see qPCR primer list) on a Chromo4 Real-Time PCR Detector (BioRad). Transcripts were quantified by the $\Delta \Delta \mathrm{C}(\mathrm{t})$ method (Livak and Schmittgen 2001) and normalized to a transcript level of a reference gene (rp49).

\section{Prediction of transmembrane motifs in CG5508}

For prediction of transmembrane motifs we used following programs: TMHMM Server v. 2.0, HMMTOP 2.1, SOSUIsignal using standard settings.

\section{DATA DEPOSITION}

Small RNA libraries were deposited in the Gene Expression Omnibus (GEO) database (www.ncbi.nlm.nih.gov/geo/) under accession no. GSE46422. Transcriptom libraries were deposited in the GEO database under accession no. GSE46423.

\section{SUPPLEMENTAL MATERIAL}

Supplemental material is available for this article.

\section{ACKNOWLEDGMENTS}

We thank Charles Zuker for providing the EMS mutagenized strains used for our screen. We thank Bill Theurkauf and Mikiko Siomi for sharing antibodies, Yuzo Niki for providing the OSS cell line, and Astrid Haase and Paloma Guzzardo for purification of Piwi and 
Aub antibodies and for helpful discussion. We thank Ben Czech and Jon Preall for critical reading of the manuscript, Taqman qPCR primers, advice regarding the immunofluorescence assay, and pValium-20 cloning. We thank Jinbiao Ma for the advice on prediction of CG5508 secondary structure. We thank Michelle Rooks, Dick McCombie, Elena Ghiban, Danea Rebbolini, and Laura Cardone for help with Illumina sequencing. We thank Assaf Gordon for help with data analysis. G.J.H. is an investigator of the Howard Hughes Medical Institute. K.A.W. is a George A. and Marjorie H. Anderson Fellow of the Watson School of Biological Sciences. This work was supported by a kind gift from Kathryn W. Davis and a grant from the National Institutes of Health to G. J.H. (5R01GM062534).

Received April 19, 2013; accepted April 23, 2013.

\section{NOTE ADDED IN PROOF}

While this paper was being reviewed, a report suggested a function of the murine homolog of CG5508 in the piRNA pathway (Shiromoto et al. 2013).

\section{REFERENCES}

Anand A, Kai T. 2011. The tudor domain protein Kumo is required to assemble the nuage and to generate germline piRNAs in Drosophila. EMBO J 31: 870-882.

Anders S, Huber W. 2010. Differential expression analysis for sequence count data. Genome Biol 11: R106.

Aravin AA, Lagos-Quintana M, Yalcin A, Zavolan M, Marks D, Snyder B, Gaasterland T, Meyer J, Tuschl T. 2003. The small RNA profile during Drosophila melanogaster development. Dev Cell 5: 337-350.

Aravin AA, Hannon GJ, Brennecke J. 2007. The Piwi-piRNA pathway provides an adaptive defense in the transposon arms race. Science 318: 761-764.

Aravin AA, Sachidanandam R, Bourc'his D, Schaefer C, Pezic D, Toth KF, Bestor T, Hannon GJ. 2008. A piRNA pathway primed by individual transposons is linked to de novo DNA methylation in mice. Mol Cell 31: 785-799.

Armour CD, Castle JC, Chen R, Babak T, Loerch P, Jackson S, Shah JK, Dey J, Rohl CA, Johnson JM, et al. 2009. Digital transcriptome profiling using selective hexamer priming for cDNA synthesis. Nat Methods 6: 647-649.

Brennecke J, Aravin AA, Stark A, Dus M, Kellis M, Sachidanandam R, Hannon GJ. 2007. Discrete small RNA-generating loci as master regulators of transposon activity in Drosophila. Cell 128: 1089-1103.

Brennecke J, Malone CD, Aravin AA, Sachidanandam R, Stark A, Hannon GJ. 2008. An epigenetic role for maternally inherited piRNAs in transposon silencing. Science 322: 1387-1392.

Chen C, Nott TJ, Jin J, Pawson T. 2011. Deciphering arginine methylation: Tudor tells the tale. Nat Rev Mol Cell Biol 12: 629-642.

Choi SY, Huang P, Jenkins GM, Chan DC, Schiller J, Frohman MA. 2006. A common lipid links Mfn-mediated mitochondrial fusion and SNARE-regulated exocytosis. Nat Cell Biol 8: 1255-1262.

Cook HA, Koppetsch BS, Wu J, Theurkauf WE. 2004. The Drosophila SDE3 homolog armitage is required for oskar mRNA silencing and embryonic axis specification. Cell 116: 817-829.

Ghildiyal M, Zamore PD. 2009. Small silencing RNAs: An expanding universe. Nat Rev Genet 10: 94-108.

Gillespie DE, Berg CA. 1995. Homeless is required for RNA localization in Drosophila oogenesis and encodes a new member of the DE-H family of RNA-dependent ATPases. Genes Dev 9: 2495-2508.

Gunawardane LS, Saito K, Nishida KM, Miyoshi K, Kawamura Y, Nagami T, Siomi H, Siomi MC. 2007. A slicer-mediated mechanism for repeat-associated siRNA $5^{\prime}$ end formation in Drosophila. Science 315: $1587-1590$.

Haase AD, Fenoglio S, Muerdter F, Guzzardo PM, Czech B, Pappin DJ, Chen C, Gordon A, Hannon GJ. 2010. Probing the initiation and effector phases of the somatic piRNA pathway in Drosophila. Genes Dev 24: 2499-2504.

Handler D, Olivieri D, Novatchkova M, Gruber FS, Meixner K, Mechtler K, Stark A, Sachidanandam R, Brennecke J. 2011. A systematic analysis of Drosophila TUDOR domain-containing proteins identifies Vreteno and the Tdrd 12 family as essential primary piRNA pathway factors. EMBO J 30: 3977-3993.

Heath RJ, Rock CO. 1998. A conserved histidine is essential for glycerolipid acyltransferase catalysis. J Bacteriol 180: 1425-1430.

Huang H, Gao Q, Peng X, Choi SY, Sarma K, Ren H, Morris AJ, Frohman MA. 2011. piRNA-associated germline nuage formation and spermatogenesis require MitoPLD profusogenic mitochondrial-surface lipid signaling. Dev Cell 20: 376-387.

Ipsaro JJ, Haase AD, Knott SR, Joshua-Tor L, Hannon GJ. 2012. The structural biochemistry of Zucchini implicates it as a nuclease in piRNA biogenesis. Nature 491: 279-283.

Kawaoka S, Izumi N, Katsuma S, Tomari Y. 2011. 3' end formation of PIWI-interacting RNAs in vitro. Mol Cell 43: 1015-1022.

Kelley LA, Sternberg MJ. 2009. Protein structure prediction on the Web: A case study using the Phyre server. Nat Protoc 4: 363-371.

Khurana JS, Theurkauf WE. 2008. piRNA function in germline development. In StemBook (ed. The Stem Cell Research Community), doi/ 10.3824/stembook.1.12.1, http://www.stembook.org. Cambridge, MA.

Klattenhoff C, Xi H, Li C, Lee S, Xu J, Khurana JS, Zhang F, Schultz N, Koppetsch BS, Nowosielska A, et al. 2009. The Drosophila HP1 homolog Rhino is required for transposon silencing and piRNA production by dual-strand clusters. Cell 138: 1137-1149.

Koundakjian EJ, Cowan DM, Hardy RW, Becker AH. 2004. The Zuker collection: A resource for the analysis of autosomal gene function in Drosophila melanogaster. Genetics 167: 203-206.

Lim AK, Kai T. 2007. Unique germ-line organelle, nuage, functions to repress selfish genetic elements in Drosophila melanogaster. Proc Natl Acad Sci 104: 6714-6719.

Livak KJ, Schmittgen TD. 2001. Analysis of relative gene expression data using real-time quantitative PCR and the $2_{\mathrm{T}}^{-\Delta \Delta C}$ method. Methods 25: 402-408.

Malone CD, Brennecke J, Dus M, Stark A, McCombie WR, Sachidanandam R, Hannon GJ. 2009. Specialized piRNA pathways act in germline and somatic tissues of the Drosophila ovary. Cell 137: 522-535.

Morawe T, Honemann-Capito M, von Stein W, Wodarz A. 2011. Loss of the extraproteasomal ubiquitin receptor Rings lost impairs ring canal growth in Drosophila oogenesis. J Cell Biol 193: 71-80.

Ni JQ, Zhou R, Czech B, Liu LP, Holderbaum L, Yang-Zhou D, Shim HS, Tao R, Handler D, Karpowicz P, et al. 2011. A genomescale shRNA resource for transgenic RNAi in Drosophila. Nat Methods 8: 405-407.

Niki Y, Yamaguchi T, Mahowald AP. 2006. Establishment of stable cell lines of Drosophila germ-line stem cells. Proc Natl Acad Sci 103: 16325-16330.

Nishimasu H, Ishizu H, Saito K, Fukuhara S, Kamatani MK, Bonnefond L, Matsumoto N, Nishizawa T, Nakanaga K, Aoki J, et al. 2012. Structure and function of Zucchini endoribonuclease in piRNA biogenesis. Nature 491: 284-287.

Olivieri D, Sykora MM, Sachidanandam R, Mechtler K, Brennecke J. 2010. An in vivo RNAi assay identifies major genetic and cellular requirements for primary piRNA biogenesis in Drosophila. EMBO J 29: 3301-3317.

Olivieri D, Senti KA, Subramanian S, Sachidanandam R, Brennecke J. 2012. The cochaperone shutdown defines a group of biogenesis factors essential for all piRNA populations in Drosophila. Mol Cell 47: 954-969. 
Pane A, Wehr K, Schupbach T. 2007. zucchini and squash encode two putative nucleases required for rasiRNA production in the Drosophila germline. Dev Cell 12: 851-862.

Pek JW, Anand A, Kai T. 2012. Tudor domain proteins in development. Development 139: 2255-2266.

Pillai RS, Chuma S. 2012. piRNAs and their involvement in male germline development in mice. Dev Growth Differ 47: 970-979.

Preall JB, Czech B, Guzzardo PM, Muerdter F, Hannon GJ. 2012. shutdown is a component of the Drosophila piRNA biogenesis machinery. RNA 18: 1446-1457.

Quinlan AR, Hall IM. 2010. BEDTools: A flexible suite of utilities for comparing genomic features. Bioinformatics 26: 841-842.

Saito K, Inagaki S, Mituyama T, Kawamura Y, Ono Y, Sakota E, Kotani H, Asai K, Siomi H, Siomi MC. 2009. A regulatory circuit for piwi by the large Maf gene traffic jam in Drosophila. Nature 461: 1296-1299.

Saito K, Ishizu H, Komai M, Kotani H, Kawamura Y, Nishida KM, Siomi H, Siomi MC. 2011. Roles for the Yb body components Armitage and $\mathrm{Yb}$ in primary piRNA biogenesis in Drosophila. Genes Dev 24: 2493-2498.

Sasnauskas G, Zakrys L, Zaremba M, Cosstick R, Gaynor JW, Halford SE, Siksnys V. 2010. A novel mechanism for the scission of doublestranded DNA: Bfil cuts both $3^{\prime}-5^{\prime}$ and $5^{\prime}-3^{\prime}$ strands by rotating a single active site. Nucleic Acids Res 38: 2399-2410.

Shiromoto Y, Kuramochi-Miyagawa S, Daiba A, Chuma S, Katanaya A, Katsumata A, Nishimura K, Ohtaka M, Nakanishi M, Nakamura T, et al. 2013. GPAT2, a mitochondrial outer membrane protein, in piRNA biogenesis in germline stem cells. RNA 19: 803-810.

Siomi MC, Sato K, Pezic D, Aravin AA. 2011. PIWI-interacting small RNAs: The vanguard of genome defence. Nat Rev Mol Cell Biol 12: 246-258.

Takeuchi K, Reue K. 2009. Biochemistry, physiology, and genetics of GPAT, AGPAT, and lipin enzymes in triglyceride synthesis. Am J Physiol Endocrinol Metab 296: E1195-E1209.
Tal MC, Iwasaki A. 2011. Mitoxosome: A mitochondrial platform for cross-talk between cellular stress and antiviral signaling. Immunol Rev 243: 215-234.

Vagin VV, Sigova A, Li C, Seitz H, Gvozdev V, Zamore PD. 2006. A distinct small RNA pathway silences selfish genetic elements in the germline. Science 313: 320-324.

Voigt F, Reuter M, Kasaruho A, Schulz EC, Pillai RS, Barabas O. 2012. Crystal structure of the primary piRNA biogenesis factor Zucchini reveals similarity to the bacterial PLD endonuclease Nuc. RNA 18: 2128-2134.

Wakimoto BT, Lindsley DL, Herrera C. 2004. Toward a comprehensive genetic analysis of male fertility in Drosophila melanogaster. Genetics 167: 207-216.

Watanabe T, Chuma S, Yamamoto Y, Kuramochi-Miyagawa S, Totoki Y, Toyoda A, Hoki Y, Fujiyama A, Shibata T, Sado T, et al. 2011. MITOPLD is a mitochondrial protein essential for nuage formation and piRNA biogenesis in the mouse germline. Dev Cell 20: 364-375.

Wilson JE, Connell JE, Macdonald PM. 1996. aubergine enhances oskar translation in the Drosophila ovary. Development 122: 16311639.

Zamparini AL, Davis MY, Malone CD, Vieira E, Zavadil J, Sachidanandam R, Hannon GJ, Lehmann R. 2011. Vreteno, a gonad-specific protein, is essential for germline development and primary piRNA biogenesis in Drosophila. Development 138: 40394050.

Zhang Z, Xu J, Koppetsch BS, Wang J, Tipping C, Ma S, Weng Z, Theurkauf WE, Zamore PD. 2011. Heterotypic piRNA Ping-Pong requires qin, a protein with both E3 ligase and Tudor domains. Mol Cell 44: 572-584.

Zhao Y, Stuckey JA, Lohse DL, Dixon JE. 1997. Expression, characterization, and crystallization of a member of the novel phospholipase D family of phosphodiesterases. Protein Sci 6: 2655-2658. 

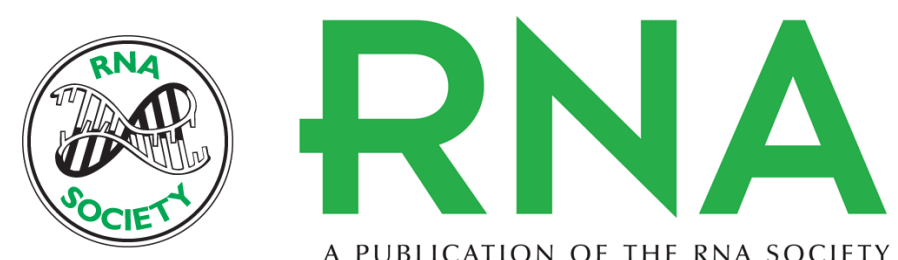

A PUBLICATION OF THE RNA SOCIETY

\section{Minotaur is critical for primary piRNA biogenesis}

Vasily V. Vagin, Yang Yu, Anna Jankowska, et al.

RNA 2013 19: 1064-1077 originally published online June 20, 2013

Access the most recent version at doi:10.1261/rna.039669.113

Supplemental Material

References

Creative Commons License

Email Alerting Service
http://rnajournal.cshlp.org/content/suppl/2013/05/10/rna.039669.113.DC1

This article cites 53 articles, 18 of which can be accessed free at: http://rnajournal.cshlp.org/content/19/8/1064.full.html\#ref-list-1

This article is distributed exclusively by the RNA Society for the first 12 months after the full-issue publication date (see http://rnajournal.cshlp.org/site/misc/terms.xhtml). After 12 months, it is available under a Creative Commons License (Attribution-NonCommercial 3.0 Unported), as described at http://creativecommons.org/licenses/by-nc/3.0/.

Receive free email alerts when new articles cite this article - sign up in the box at the top right corner of the article or click here. 